\title{
Effects of Holmium Additions on Microstructure and Properties of A356 Aluminum Alloys
}

\author{
Qiang Wang, Zhiming Shi *, Hong Li, Yaming Lin, Ningyu Li, Tianhao Gong, Ruiying Zhang and \\ Huimin Liu
}

School of Materials Science and Engineering, Inner Mongolia University of Technology, Hohhot 010051, China; qwang@163.com (Q.W.); lih@sina.com (H.L.); liny00@163.com (Y.L.); ylnd@163.com (N.L.);

TianhaoGong@163.com (T.G.); zhangr@imut.edu.cn (R.Z.); Huimin@imut.edu.cn (H.L.)

* Correspondence: shizm@imut.edu.cn; Tel.: +86-471-657-5752

Received: 7 October 2018; Accepted: 17 October 2018; Published: 19 October 2018

\begin{abstract}
Sr-modification of A356 alloys has distinct shortages due to the volatilization and oxidation during remelting and pouring, which often reduce the modification efficiency and mechanical properties of the alloys. To avoid the adverse effects and enhance the comprehensive properties, the effects of heavy rare earth element holmium (Ho) modification on the microstructure and properties of the alloy were investigated. Ho addition inhibited the intrinsic orientation growth of $(111)_{\mathrm{Al}}$ planes and stimulated the growth of the $(200)_{\mathrm{Al}}$ planes for $\alpha$-Al crystals. The addition of $0.2 \mathrm{wt} . \%$ Ho produced the best refinement effect for $\alpha$-Al grains; $0.3 \mathrm{wt} . \%$ of Ho addition yielded the most distinct modification effect for eutectic Si phases, which was further improved by a T6 treatment. The extra addition of $0.4 \mathrm{wt} . \%$ Ho resulted in the complete loss of the refinement and modification effects and in the abnormal growth of the $\alpha$ - $\mathrm{Al}$ crystals. Ho additions produced $\mathrm{Al}_{3} \mathrm{Ho}$ phases containing Fe elements, which were distributed on the boundaries of the $\alpha$-Al dendrites. The corrosion-proof performance was enhanced by Ho addition and the T6 treatment; the tensile strength and elongation achieved the highest value upon $0.2 \mathrm{wt} . \%$ of Ho addition and the $\mathrm{T} 6$ treatment. Moreover, the hardness was also enhanced by Ho additions in both states.
\end{abstract}

Keywords: aluminum alloy; modification; rare earth; holmium; microstructure; corrosion; mechanical property

\section{Introduction}

A356 aluminum alloy is an important structural material, which is substantially used to fabricate vehicle wheels and in the assembly of cylinders due to its high specific strength, good castability, and lower cost. At present, a duplex treatment of Al-Ti-B refinement and Sr modification is widely applied for A356 melts to improve the microstructure and mechanical properties [1-3]. However, use of the Sr modifier easily results in volatilization and oxidation during remelting and pouring processes because of its lower melting point and higher chemical activity, which often generate pores and slags in the alloy, reducing the modification efficiency and deteriorating the properties.

In contrast, rare earth (RE) elements are special modifiers, which have higher melting points and activity and are not easy to volatilize and oxidize in aluminum melts with a higher purity. The mortification effects of light REs such as La, Ce, Sc and heavy REs such as Er, Gd, Y were investigated for A356 alloys. It was reported that larger than $0.3 \mathrm{wt} . \%$ additions of La, Ce or their mixtures produced full modification for eutectic $\mathrm{Si}$; while the strength was not largely improved [4-7]. Sc addition refined the primary $\alpha-\mathrm{Al}$ crystals as the $\mathrm{Al}_{3} \mathrm{Sc}$ precipitations act as heterogeneous nucleation sites; however, it had a much weaker modification effect on eutectic Si phases [8]. Totals of 0.2 to $0.3 \mathrm{wt} . \%$ of Er or Gd additions greatly improved the microstructure and mechanical properties through 
grain refinement and the adjustment of the Si morphology. Extra additions made the Al-Er and Al-Gd intermetallics continuously distribute in grain boundaries [9,10]; while $Y$ addition inversely coarsened the $\alpha$-Al crystals due to precipitation of the $\mathrm{Al}_{3} \mathrm{Y}$ compounds [11]. Moreover, the modification effect of Er and Nd on eutectic and hypereutectic Al-Si alloys was also found, and the optimized additions were increased [12-15]. It can be recognized that the modification effects of REs for A356 aluminum alloys are quite different; this is mainly correlated with the differences in physicochemical properties.

Heavy rare earth of holmium (Ho) was found to have a modification effect on the microstructure of A356 aluminum alloys in the as-cast state; while the precipitation of more $\mathrm{Al}_{3}$ Ho compounds existed in grain boundaries, damaging the continuity of Al matrix [16]. In the vacuum-evaporated Al-Ho thin films, the grain size varied with the Ho content, and the axial texture and the texture axis were determined by the amount of Ho [17]. Moreover, larger than $1.0 \mathrm{wt} \%$ of Ho addition yielded the optimized corrosion resistance for the $\mathrm{Mg}-\mathrm{Al}$ alloys, which increased upon increasing the Ho content. The magnesium alloys containing $1.10 \%$ and $2.16 \%$ Ho exhibited better corrosion resistance $[18,19]$. Ho addition refined the microstructure and enhanced the strength, plasticity, and hardness of the $\mathrm{Mg}-\mathrm{Li}$ and Mg-Nd alloys; the thermo-mechanically treated Mg-8Li-3Al-3Ho alloys exhibited an increased elongation of $21.4 \%$ [20-22]. The effects of Ho addition on the microstructure and properties of Ni- and $\mathrm{Nb}$-based alloys were also investigated; minor Ho addition resulted in the $\mathrm{Ni}_{2} \mathrm{Al}_{3} \mathrm{Ho}$ phases, refined the lamella in eutectic cells, and resisted the coarsening of intercellular regions. A total of $0.1 \mathrm{wt} . \%$ of Ho addition significantly improved the elevated temperature strength of the NiAl-28Cr-6Mo- $0.2 \mathrm{Hf}$ alloy at a higher strain rate, while the strengthening effect becomes weaker at a lower strain rate for the Nb-22Ti-16Si-7Cr-3Al-3Ta-2Hf alloy [23-25].

The heavy RE Ho is different from other light and heavy REs in physicochemical parameters such as atomic radius, electronegativity, solubility in $\alpha$-Al crystals, eutectic temperature, and the Al-RE eutectic composition [26-29]. On the other hand, the Al-Ti-B refinement and Sr modification hardly enhance the hardness and corrosion-proof properties. With an increasing demand for products of the A356 alloys and applications in rigorous cases such as heavy load, wear, and corrosion, the comprehensive properties should be further improved. However, Ho is not deeply investigated. The positive effects of Ho on the magnesium alloys, high-temperature alloys, and others have been confirmed. However, its modification effect has not been paid great attention. Therefore, the present work aims to investigate the effects of Ho modification on the microstructure and the mechanical and corrosion-proof properties of A356 aluminum alloys and to compare the difference in modification behaviors between Ho and light RE of La/Ce, hoping to find a new kind of modifier.

\section{Materials and Methods}

Commercial A356 aluminum alloy ingot (7.1 wt.\% Si, 0.45 wt.\% Mg, 0.10 wt.\% Fe) and Al-Ho master alloy (9.96 wt.\% Ho) were used as raw materials. The A356 ingot ( $3 \mathrm{~kg}$ ) was melted in an induction furnace at $760{ }^{\circ} \mathrm{C}$; the master alloy was added to form five groups of samples with different Ho contents $(0,0.1,0.2,0.3$, and $0.4 \mathrm{wt} . \%)$. Filtration (alumina porous ceramic disk with a pore size of $1 \mathrm{~mm}$ and a thickness of $20 \mathrm{~mm}$, preheated to $500{ }^{\circ} \mathrm{C}$ ) and $\mathrm{N}_{2}$ gas purification (with a flux of $800 \mathrm{~mL} / \mathrm{min}$ for $5 \mathrm{~min}$ ) were used to eliminate inclusions and gases in the melts. When the temperature decreased to $730{ }^{\circ} \mathrm{C}$, the melts were poured into a preheated steel mold $\left(250^{\circ} \mathrm{C}\right)$ to form bars $(\varphi 15 \mathrm{~mm})$ and cooled to room temperature. The samples were then treated with a T6 schedule (soaking at $535^{\circ} \mathrm{C}$ for $4 \mathrm{~h}$, quenched in water $\left(100^{\circ} \mathrm{C}\right)$, soaking at $200^{\circ} \mathrm{C}$ for $4 \mathrm{~h}$ and cooled in air) [9].

A metallurgical microscope (OLYMPUS-GX51) (Olympus, Hangzhou, China) was used to observe the microstructure. A 0.5 vol.\% of HF solution was used as the etching reagent. An image analysis software (SISC IAS V8.0) (SISC, Beijing, China) was adopted to statistically analyze grain size and the aspect ratio of Si phases against 20 fields; a series of photographic processes such as gray level transfer, image filtering, image splitting, edge strengthening, image binarizing, boundary tailoring, and boundary linearizing were used to obtain clear images suitable to recognize and calculate automatically. A scanning electronic microscope (SEM, S3400-N, Hitachi, Tokyo, Japan) with an energy dispersive 
spectrometer (EDS, 7021-H, HORIBA, Kyoto, Japan) was applied to inspect the morphology and composition of phases. An X-ray diffractometer (XRD, D/MAX-2500/PC, PIGAKV, Rigaku, Tokyo, Japan), was used to analyze the phase compositions, using copper Ka radiation, at $40 \mathrm{kV} / 200 \mathrm{~mA}$ and a scanning speed of $1^{\circ} / \mathrm{min}$. An electrochemical workstation (Zennium, Zahner, Germany) was applied to measure the potential polarization curves; the contact area was $10 \times 10 \mathrm{~mm}$ and the scanning speed was controlled to be $10 \mathrm{mV} / \mathrm{s}$. A material test machine (SHT4605, Kason, Jinan, China) was adopted to examine the strength and elongation against five samples $(\varphi 10 \times 50 \mathrm{~mm})$ for each group at a loading speed of $1.0 \mathrm{~mm} / \mathrm{min}$. A hardness tester (HVS-30ZLCD, Shanghai Precision Instrument Co. Ltd., Huayin, China) was used to measure the hardness (HB) against five points for each group; the applied load was $62.5 \mathrm{Kg}$ and a quenched steel ball with a diameter of $5 \mathrm{~mm}$ was used.

\section{Results}

\subsection{Microstructure of the Ho-Modified A356 Alloys in as-Cast and T6 States}

The microstructure of the as-cast alloys modified with different amounts of Ho is shown in Figure 1 . Additions of $0.1 \mathrm{wt} . \%$ and $0.2 \mathrm{wt} . \%$ of Ho refined the $\alpha$-Al crystals, see Figure $1 \mathrm{~b}-\mathrm{c} ; \mathrm{while}$ 0.2 wt. $\%$ and 0.3 wt. \% of Ho additions yielded the distinct modification effect; the eutectic Si occurred in the form of short rods and fine particles, as shown in Figure 1c-d. A $0.3 \mathrm{wt} . \%$ of Ho addition yielded the best modification effect; however, the abnormal $\alpha$-Al crystals were formed. The extra addition of $0.4 \mathrm{wt} . \%$ of Ho lead to the complete loss of the refinement and modification effects, see Figure 1e.
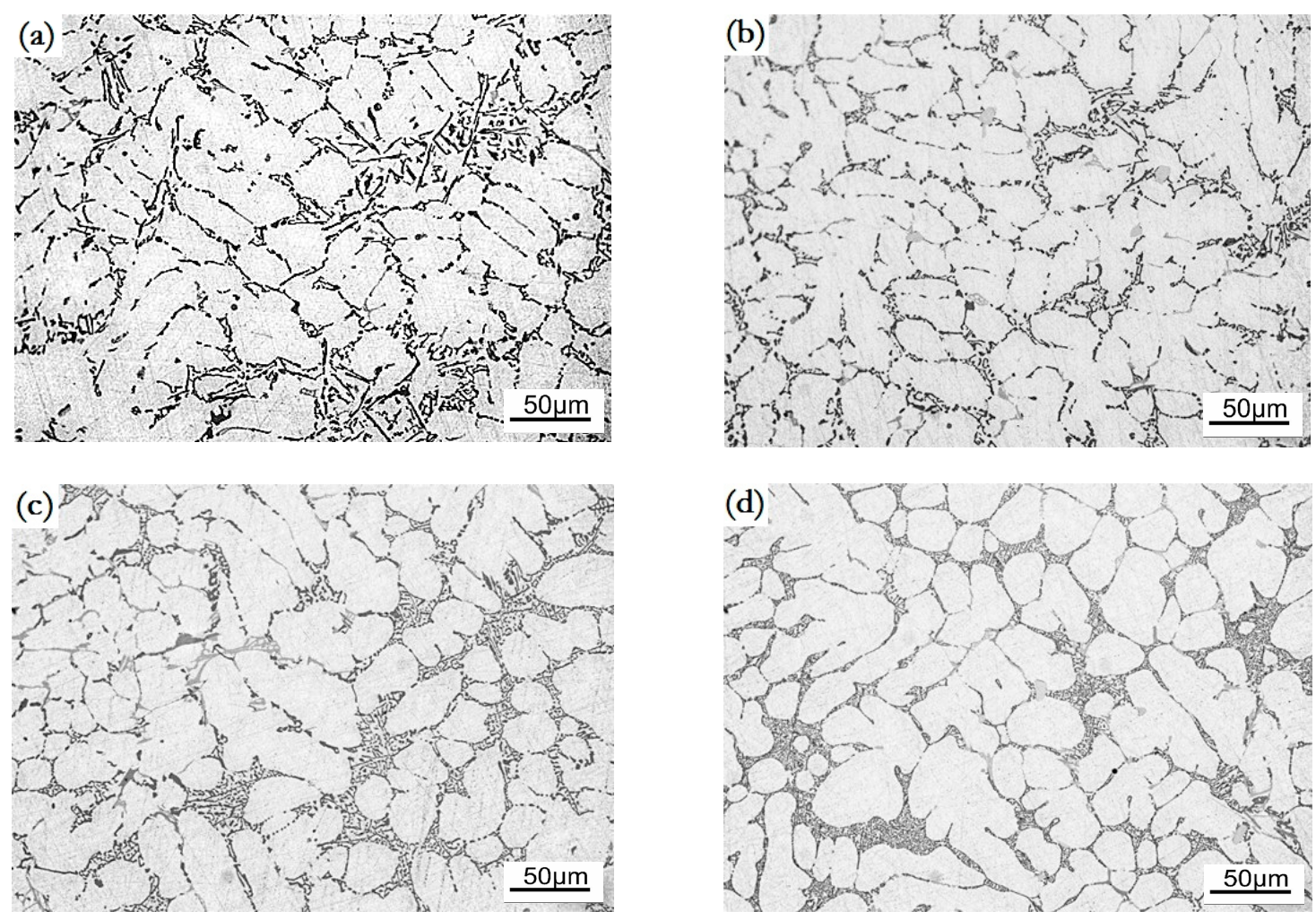

Figure 1. Cont. 


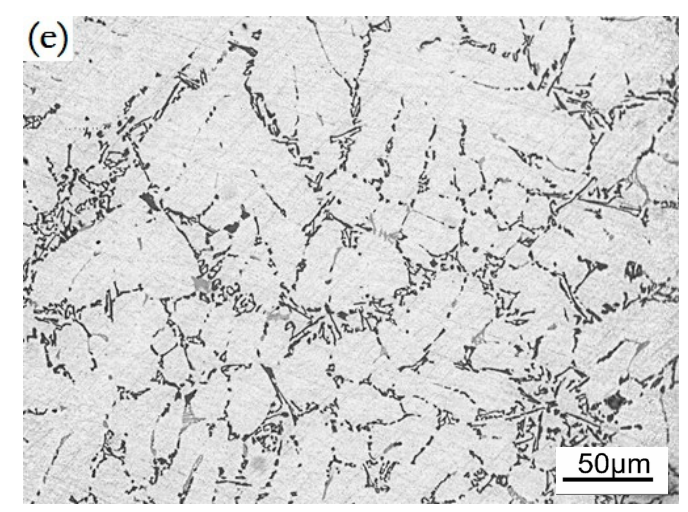

Figure 1. Microstructure of the Ho-modified A356 aluminum alloys in as-cast state, (a) unmodified; (b) 0.1 wt.\%; (c) 0.2 wt.\%; (d) 0.3 wt.\%; (e) 0.4 wt.\%.

A T6 treatment greatly increased the percentage of fine Si particles, especially in the cases of $0.2 \mathrm{wt} . \%$ and $0.3 \mathrm{wt} . \%$ modifications, see Figure $2 \mathrm{c}-\mathrm{d}$. In a word, the $0.2 \mathrm{wt} . \%$ of Ho addition had the best refinement and modification effects, which can be confirmed by a statistical analysis for the size and morphology of the $\alpha$-Al crystals and Si phases, see Figure 3.
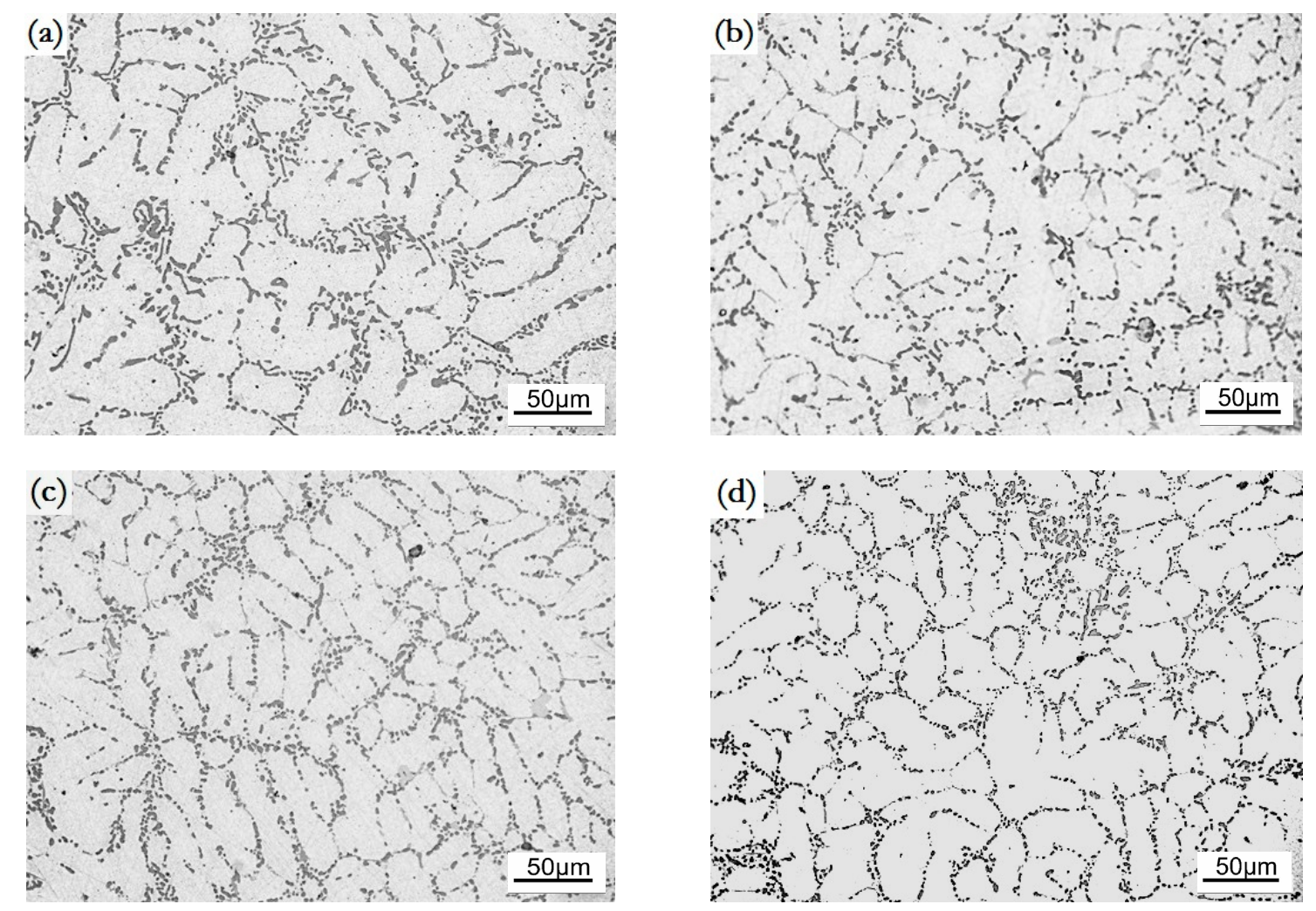

Figure 2. Cont. 


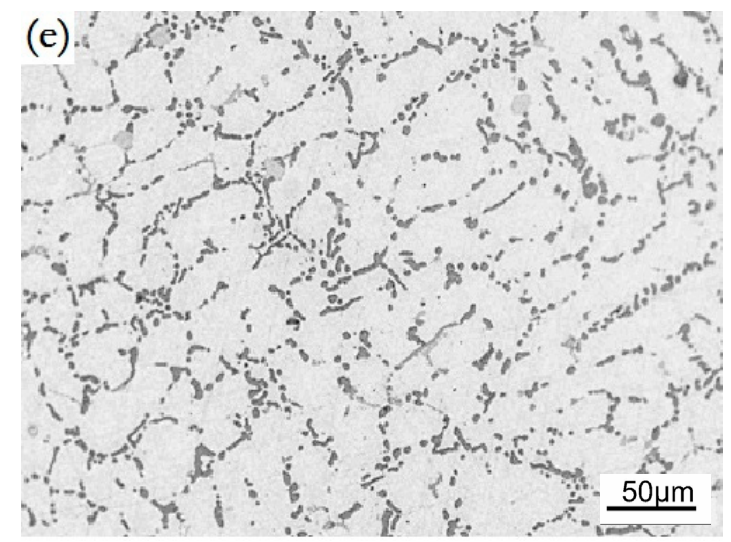

Figure 2. Microstructure of the Ho-modified A356 aluminum alloys in T6 state, (a) unmodified; (b) 0.1 wt. \%; (c) 0.2 wt. \%; (d) 0.3 wt.\%; (e) 0.4 wt.\%.
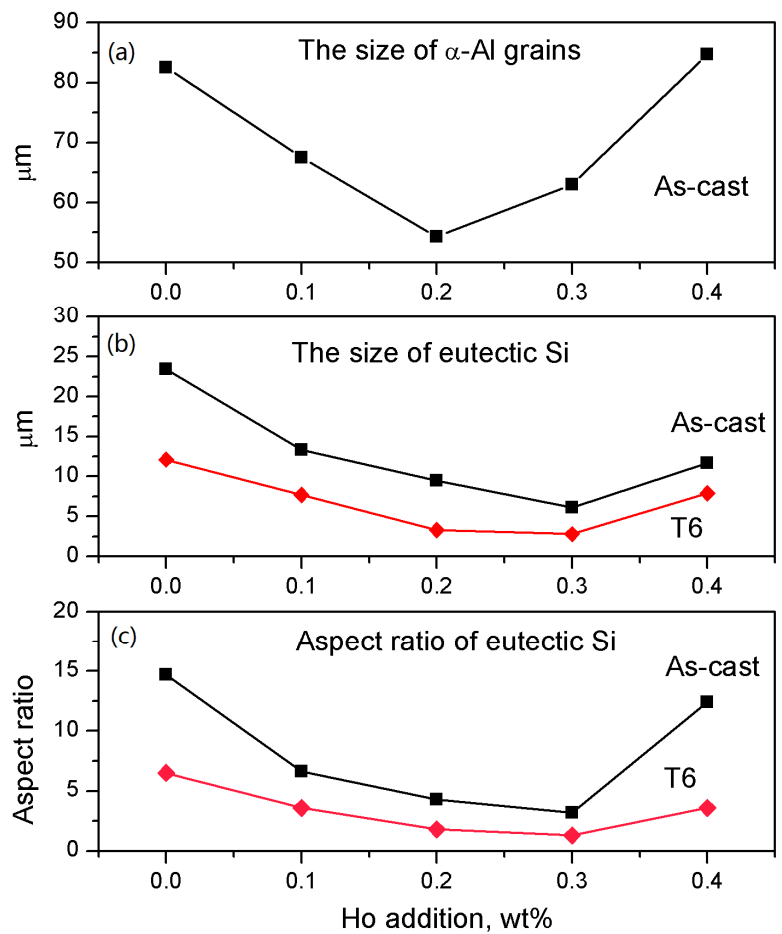

Figure 3. Variations of the statistical parameters of the size and morphology of the $\alpha-\mathrm{Al}$ crystals and $\mathrm{Si}$ phases, (a) equivalent size of $\alpha$-Al crystals; (b) equivalent size of Si phases; (c) aspect ratio of Si phases.

\subsection{Phase Analysis of the Alloys}

The Ho-modified alloys are composed of $\alpha-\mathrm{Al}, \mathrm{Si}$, and $\mathrm{Al}_{3} \mathrm{Ho}$ phases, see Figure 4 . The intensity of $\{111\}_{\mathrm{Al}}$ plane was reduced, and the $\{200\}_{\mathrm{Al}}$ plane was enhanced by a Ho addition; indicating that Ho addition inhibits the preferential orientation growth dependent on $\{111\}_{\mathrm{Al}}$ and stimulated the growth dependent on $\{200\}_{\mathrm{Al}}$. Moreover, the $\mathrm{Al}_{3} \mathrm{Ho}$ phases separately or discontinuously existed in the $\alpha$-Al grain boundaries, of which the content and size were increased with an increase of the Ho content, see Figure 5a-c. The morphology of eutectic Si was mostly converted into short rods and particles respectively by $0.2 \mathrm{wt} . \%$ and $0.3 \mathrm{wt} . \%$ additions. By the T6 treatment, the nodular eutectic Si particles with a size of less than $5 \mu \mathrm{m}$ were produced; the $\mathrm{Al}_{3} \mathrm{Ho}$ phases also changed into small bulks and short flakes, see Figure 5 d. 


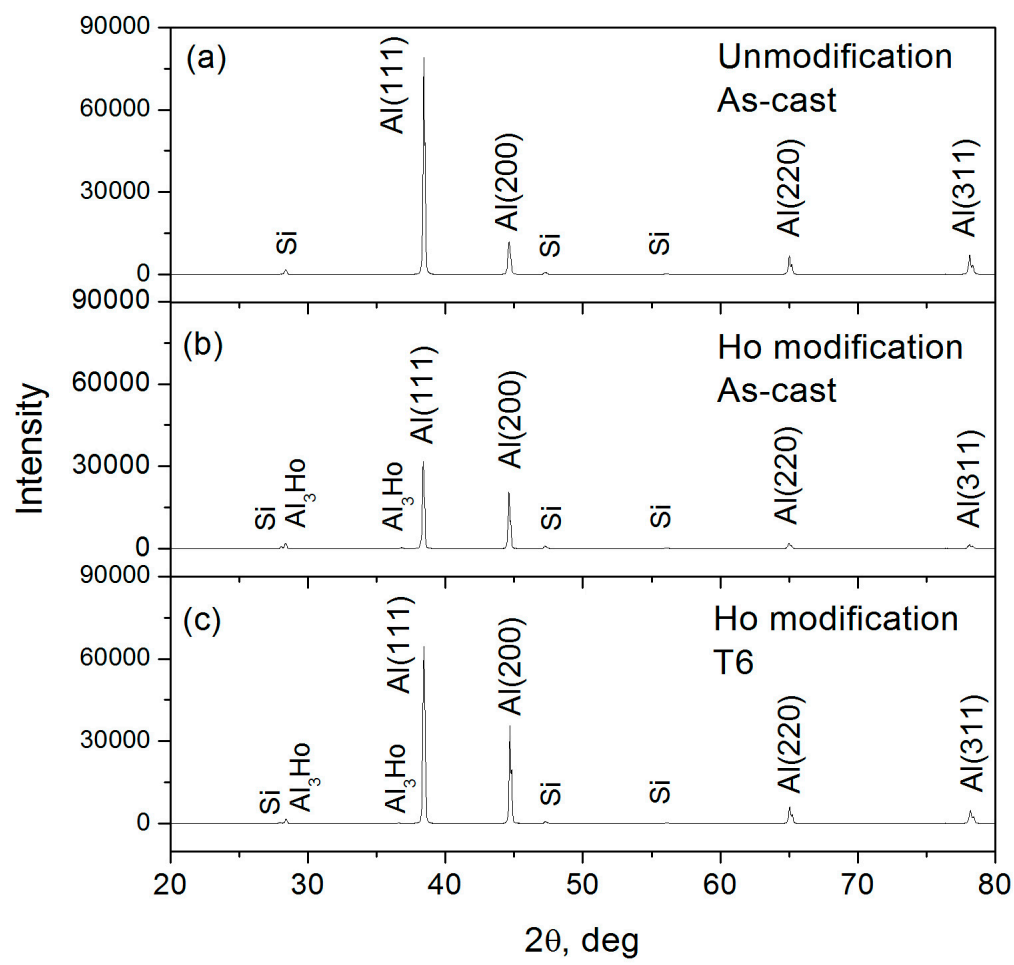

Figure 4. XRD patterns of the A356 alloys, (a) Ho-free, as-cast; (b) 0.2 wt.\% of Ho addition, as-cast; (c) $0.2 \mathrm{wt} . \%$ of Ho addition, T6.
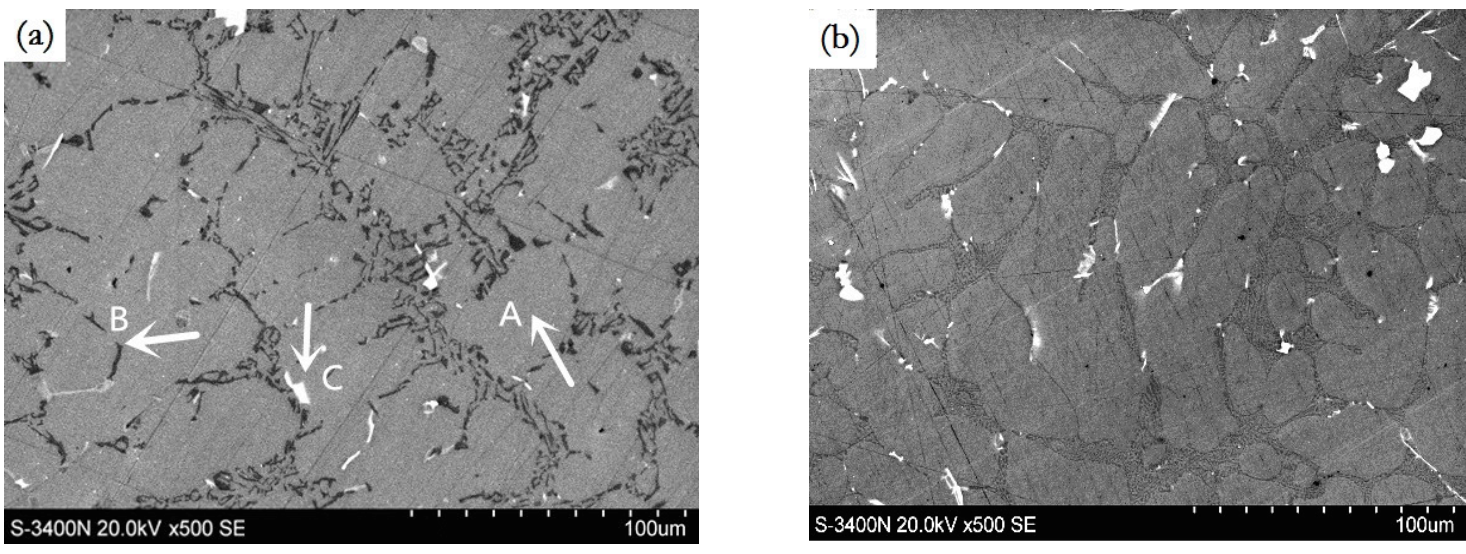

(c)
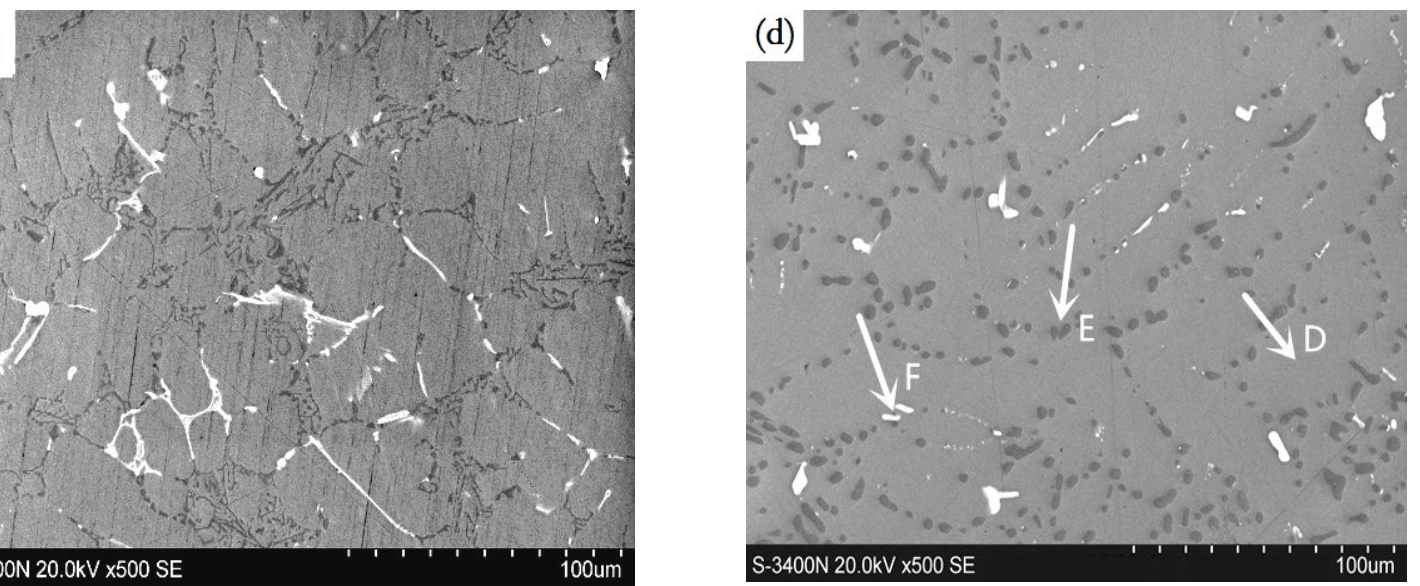

Figure 5. Cont. 


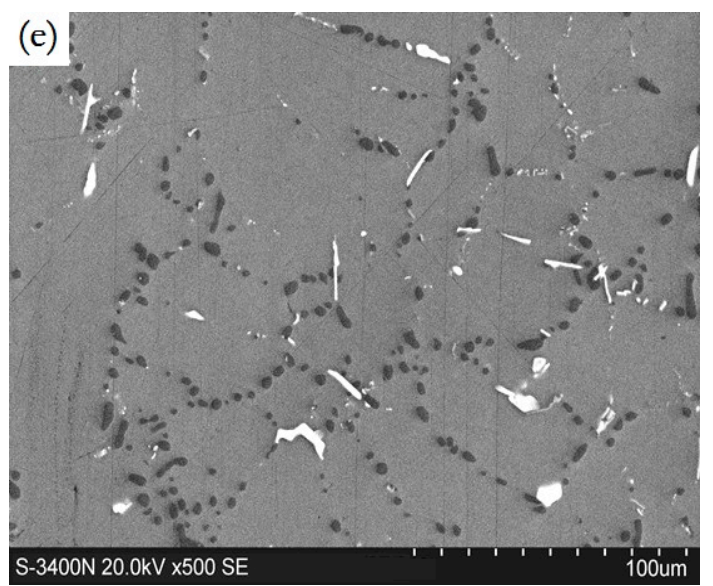

Figure 5. SEM images of the Ho-modified A356 alloys, (a) 0.2 wt.\%, as-cast; (b) 0.3 wt.\%, as-cast; (c) 0.4 wt.\%, as-cast; (d) 0.2 wt. \%, T6; (e) 0.3 wt.\%, T6.

It was found from the EDS data, shown in Figure 6, that Ho was absence in the $\alpha$-Al and Si phases in both states; the $\mathrm{Al}_{3} \mathrm{Ho}$ phases contained $\mathrm{Fe}$ atoms, which helps to eliminate the harmful effect of $\mathrm{Al}_{3}$ Fe needles.
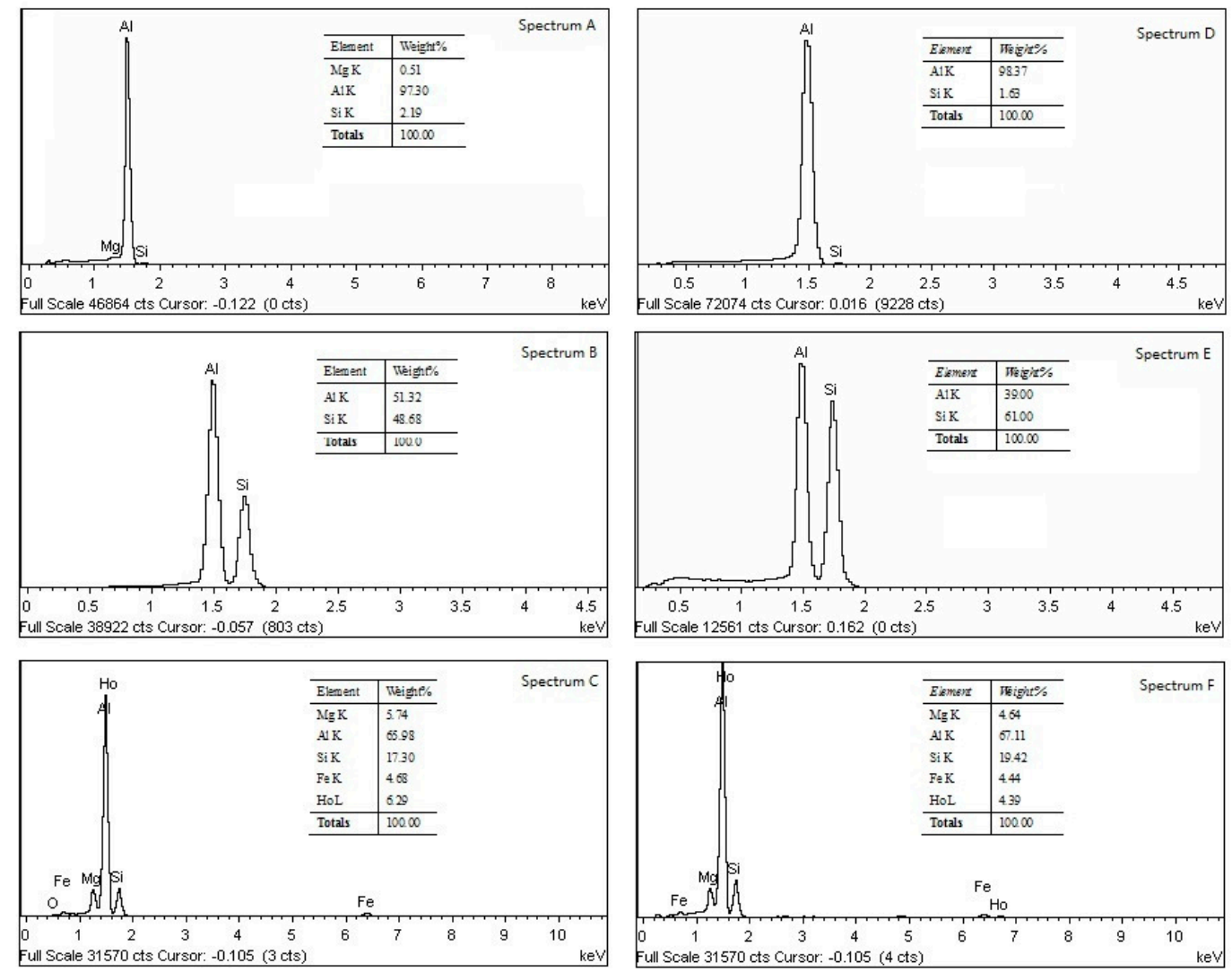

Figure 6. Elements in phases of the Ho-modified alloys by EDS.

\subsection{Mechanical Properties of the Ho-Modified Alloys}

The ultimate tensile strength was enhanced little when adding $0.1-0.2 \mathrm{wt} . \% \mathrm{Ho}$, and the elongation was gradually reduced upon increasing Ho addition in the as-cast state, see Figure 7a,b. By a T6 treatment, the tensile strength and elongation had the highest value of $286 \mathrm{MPa}$ and $8.0 \%$ respectively at $0.2 \mathrm{wt} . \%$ of Ho addition. Moreover, the hardness was also enhanced by Ho additions in both states; the hardness arrived at $77 \mathrm{HB}$ when adding $0.2 \mathrm{wt} . \%$ of Ho and in the T6 state, see Figure 7c. 
(a)

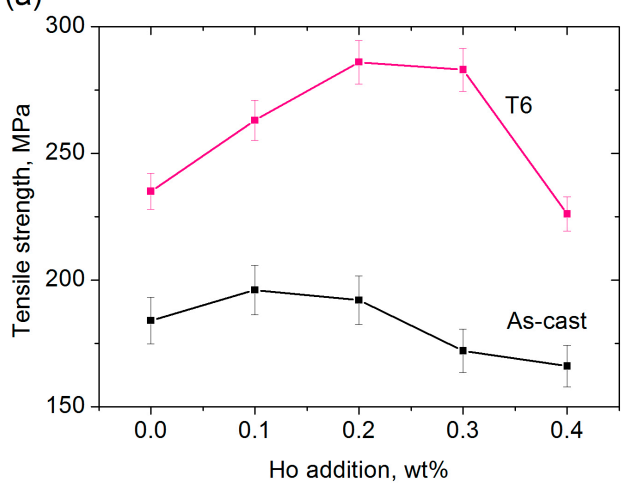

(b)

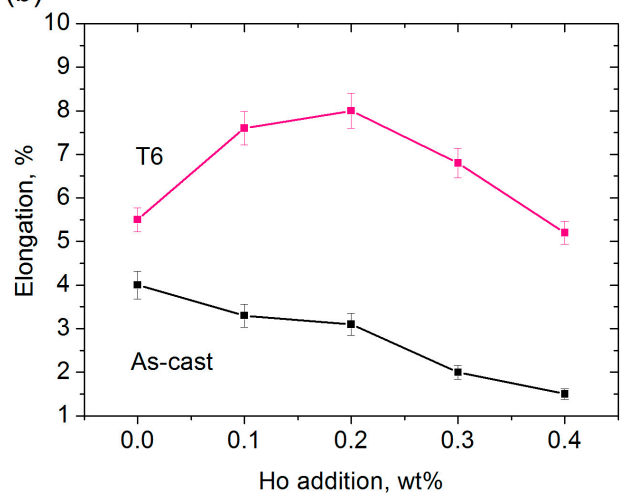

(c)

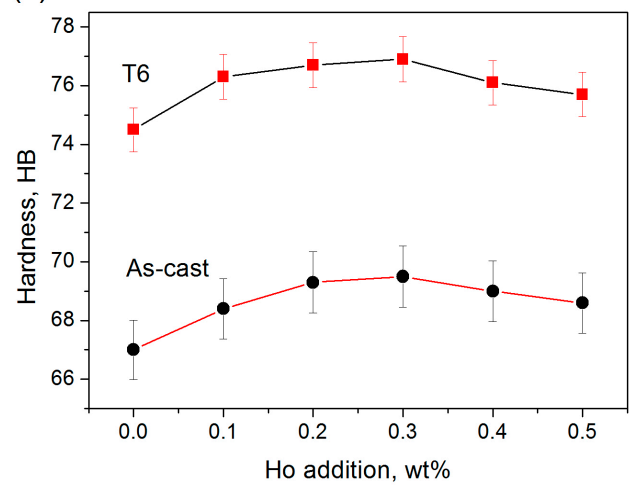

Figure 7. Mechanical properties of the Ho-modified A356 alloys, (a) tensile strength; (b) elongation; (c) hardness.

\subsection{Electrochemical Corrosion Properties of the Ho-Modified Alloys}

The corrosion potential was enhanced by a $0.2 \mathrm{wt} . \%$ of Ho addition and, especially, by the T6 treatment; the polarization potential was increased from $-0.89 \mathrm{~V}$ to $-0.81 \mathrm{~V}$ and $-0.61 \mathrm{~V}$, respectively, see Figure 8, which indicates an improvement in the corrosion resistance property of the alloy.

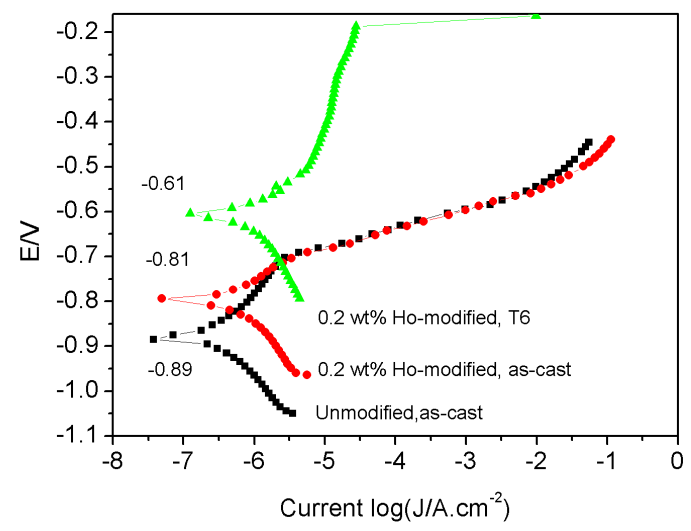

Figure 8. Potential polarization curves of the alloys in a $3.5 \mathrm{~mol} \% \mathrm{NaCl}$ solution.

\section{Discussion}

A356 aluminum alloy is a typical hypoeutectic alloy, which is mainly composed of primary $\alpha$-Al crystals and eutectic Si. By melts modifications with special compounds or elements, the microstructure can be greatly improved. For examples, the $\mathrm{TiB}_{2}, \mathrm{TiC}, \mathrm{Al}_{3} \mathrm{Sc}, \mathrm{Al}_{3} \mathrm{Y}$, and $\mathrm{Al}_{3} \mathrm{Er}$ compounds serve as 
heterogeneous nucleation sites to facilitate the nucleation of $\alpha$-Al crystals [3,6,11,13,30,31]; some active elements adsorbing on the surface of the primary $\alpha$-Al dendrites advance their flourishing growth due to constitutional supercooling [8,32]. On the other hand, elements such as $\mathrm{Sr}, \mathrm{P}, \mathrm{Na}$, and RE adsorb on the surface of the eutectic Si phases to inhibit the orientation growths along $\{200\},\{110\}$, or $\{101\}$ planes, resulting in short rods or even small granules $[13,33,34]$. With the refinement of $\alpha$-Al dendrites and the improvement in morphology of the Si phases, the mechanical properties of alloys can be enhanced.

\subsection{Effect of Ho Addition on the Crystallization of A356 Alloys}

In the present hypoeutectic Al-Si-Mg system; there are clusters of -Al-Al-, -Al-Si-, and -Si-Si-, which increase with a decrease in the melt's temperature. The -Al-Al- clusters directly construct $\alpha$-Al crystals, and the -Si-Si- clusters develop into eutectic Si phases. With Ho addition, clusters such as -Al-Ho- and -Si-Ho- are formed in melts. The Ho atom has a larger atomic radius and a lower electronegativity than those of $\mathrm{Al}$ and $\mathrm{Si}$ atoms, as shown in Table 1, and hardly dissolves in $\alpha-\mathrm{Al}$ crystals, see Figure 6 . Formation of the $\alpha$-Al crystals requires the removal of the Ho atoms to reduce the energy for nucleation and growth. Thus, crystallization of the $\alpha$-Al grains will be delayed to a lower temperature to overcome the crystallization resistance. At the same time, the discharged Ho atoms enrich the surface of the $\alpha$-Al crystals to result in a constitutional supercooling, which flourishes dendritic growth of the $\alpha$-Al crystals. Therefore, the primary $\alpha$-Al crystals can be refined.

Table 1. Physicochemical parameters of the related elements and their compounds [26-29].

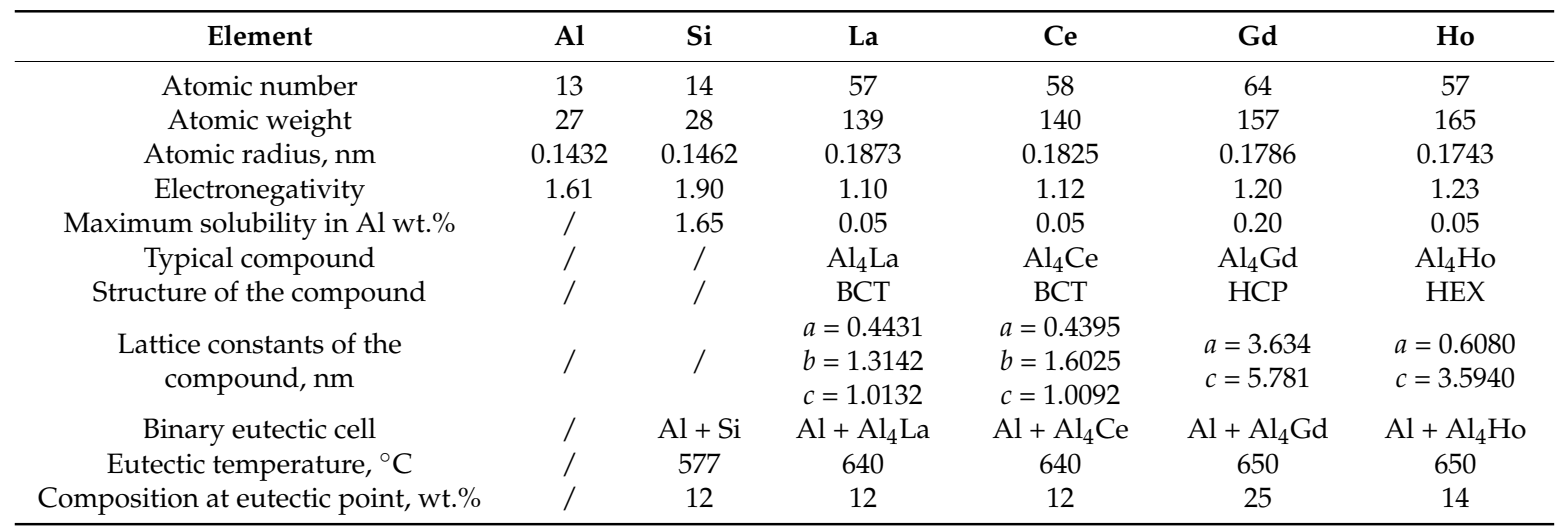

In contrast, the formation of the eutectic Si also depends on releasing Ho atoms in Si-Ho clusters. Ho has a solubility of less than 1 at.\% in Si crystals [35]. Although, it cannot be identified by EDS, see Figure 6. However, the small dissolution increases the lattice distortion energy of Si crystals and disturbs their inherent orientation growths. Moreover, adsorption of Ho onto the surface of the Si crystals also poisons the orientation growths. Thus, the short rods and small nodules of eutectic Si can be obtained.

With this deduction, an increasing addition of Ho should further increase the refinement and modification effects; in fact, the opposite is true. This is because Al-Ho clusters can also be transformed into $\mathrm{Al}_{3} \mathrm{Ho}$ phases at a higher temperature $\left(650^{\circ} \mathrm{C}\right)[36]$ than that of primary $\alpha$ - $\mathrm{Al}$ crystals $\left(615^{\circ} \mathrm{C}\right)$. Greater Ho addition intensifies the transformation tendency, see Figure $5 \mathrm{a}-\mathrm{c}$, due to an increase in the concentration. On the other hand, Ho-Si compounds, present in forms of the $\mathrm{Ho}_{5} \mathrm{Si}_{3}, \mathrm{Ho}_{5} \mathrm{Si}_{4}, \mathrm{HoSi}$, and $\mathrm{Ho}_{4} \mathrm{Si}_{5}$, with a higher $\mathrm{Ho} / \mathrm{Si}$ ratio [35] cannot be constructed in the present melts with much lower Ho concentrations. Therefore, an increase in Ho addition can influence the orientation growth of Si phases by its dissolution and adsorption, resulting in a further modification effect (at $0.3 \mathrm{wt} . \%$ ). Extra addition of Ho causes the $\mathrm{Al}_{3}$ Ho phases to produce more readily ( $0.4 \mathrm{wt}$.\% or above); thus, the modification effect cannot be further maintained. 


\subsection{Effect of Heat Treatment on the Morphology of Eutectic Si in Ho-Modified A356 Alloys}

The Ho atoms enriched on the surface of the eutectic Si increase the interfacial energy with the $\alpha$-Al crystals, which results in a spheroidization of the Si rods and nodules due to the Ostwald ripening mechanism [37]. This phenomenon always appeared in the RE-modified Al-Si alloys [5-7,9,10,15]. Moreover, Ho-dissolved Si crystals become unstable when subjected to soaking at high temperatures; the Ho atoms must be removed from the phases to reduce its solubility and the lattice distortion energy. This creates the opportunity for the needles and plates of Si phases to be broken up into short rods and small nodules at the weakly-connected parts where the Ho atoms escaped.

\subsection{Effect of Ho Addition on Mechanical and Electrochemical Properties of the Alloys}

The mechanical properties are greatly influenced by the size, morphology, and distribution of $\alpha$-Al crystals, eutectic $\mathrm{Si}$, and the $\mathrm{Al}_{3} \mathrm{Ho}$ phases. In the as-cast state, the brittle eutectic Si phases presented in the form of coarse needles and plates in the Ho-free alloy, see Figure 1a, which strongly damaged the mechanical properties and cannot be largely improved by a heat treatment, see Figure 2 a.

Ho addition refined the $\alpha$-Al crystals and greatly changed the morphology of the Si phases, see Figure $1 \mathrm{~b}-\mathrm{d}$; however, the sharp-angled and hard $\mathrm{Al}_{3}$ Ho phases existed in the boundary of $\alpha$ - $\mathrm{Al}$ grains, see Figure $5 a-c$, which also have a negative effect on the mechanical properties. Therefore, the tensile strength was increased little in the case of 0.1 to $0.2 \mathrm{wt}$.\% Ho additions, and the elongation was found to decrease with increasing Ho additions, see Figure 7.

A T6 treatment changed the short rods of eutectic Si phases into fine particles, which were uniformly distributed in the $\alpha$-Al matrix, as shown in Figure 5d,e. Moreover, the hard $\mathrm{Al}_{3} \mathrm{Ho}_{\text {phases, }}$ which have less influence on strength and elongation, were adjusted into smooth and smaller nodules and separately distributed in the matrix. A $0.2 \mathrm{wt}$.\% Ho addition yielded a compromised effect on the microstructure and mechanical properties. Although the $0.3 \mathrm{wt}$ \% Ho addition also had a better modification effect on the eutectic $\mathrm{Si}$, the hard $\mathrm{Al}_{3}$ Ho phases increased and presented the coarse sticks, which strongly deteriorated the mechanical properties. Moreover, increases in hardness are due to the hard $\mathrm{Al}_{3} \mathrm{Ho}$ phases and their dispersive distribution in the matrix by the heat treatment.

Ho addition and the T6 treatment also improved the corrosion-proof property. This is because the $\mathrm{Al}_{3} \mathrm{Ho}$ phase has a higher electrode potential than that of the $\mathrm{Al}$ matrix, which is located in the interface between $\alpha-\mathrm{Al}$ and $\mathrm{Si}$ to improve the corrosion-proof ability of the boundaries [19]. On the other hand, the Fe atoms dissolved in $\mathrm{Al}_{3} \mathrm{Ho}$ compounds, see Figure 6. Therefore, their harmful effect was reduced or eliminated. Moreover, Ho additions also purified aluminum melts by removing the inclusions and gasses [29]. Lastly, the microstructure was further stabilized by the heat treatment due to the elimination of inner-stress and the homogenization of the microstructure.

\subsection{Comparison of Modification Effects of the Ho and the La and $\mathrm{Ce}$}

Ho addition had a stronger modification effect and a higher modification efficiency in comparison with the light REs of La and Ce [4-7]; the suitable addition is lower (0.2-0.3 wt.\% Ho) for modification of the Si morphology, see Figure 3.

The bonds of Ho with $\mathrm{Al}$ and $\mathrm{Si}$ in the clusters are stronger than that of the La and Ce because Ho has a smaller atomic radius and a larger electronegativity; therefore, a stronger nucleation energy is required to release the Ho atoms in the chains. Thus, nucleation of the primary $\alpha$-Al crystals had to occur at a lower temperature, resulting in a stronger refinement effect. Moreover, the diffusive migration of the Ho atom is more difficult in melts because it has a much larger weight than that of the La and Ce atoms, which results in slower growths of $\alpha$-Al dendrites or the Si crystals. Therefore, the Ho has a stronger modification effect and higher modification efficiency than the La and Ce do. 


\section{Conclusions}

The Ho-modified A356 alloys are composed of the $\alpha-\mathrm{Al}, \mathrm{Si}$, and $\mathrm{Al}_{3} \mathrm{Ho}$ phases; Ho atoms hardly dissolve in $\alpha-\mathrm{Al}$ and Si crystals.

Ho addition changed preferential orientation growths of the $\alpha$-Al crystals by inhibiting the preferential growth of $(111)_{\mathrm{Al}}$ and stimulating the growth of (200) $\mathrm{Al}$ planes.

The addition of $0.2 \mathrm{wt}$ \% Ho produced the best refinement effect for $\alpha$-Al crystals; 0.3 wt. $\%$ of Ho yielded a distinct modification effect for eutectic Si phases, which was further improved by a T6 treatment.

Extra addition of $0.4 \mathrm{wt} . \%$ Ho resulted in the complete loss of the refinement and modification effects and resulted in the abnormal growth of the $\alpha$-Al crystals.

$\mathrm{Al}_{3} \mathrm{Ho}$ phases located between $\alpha$-Al grains and present in the form of flakes, bulks, and nets with an increase of Ho addition. A T6 treatment made them change into small nodules and rods.

Fe atoms were incorporated in $\mathrm{Al}_{3} \mathrm{Ho}$ phases during solidification, which eliminated the harmful effect of $\mathrm{Al}_{3}$ Fe needles.

An addition of $0.2 \mathrm{wt} . \%$ of Ho and the T6 treatment made the tensile strength and elongation arrive at the highest value.

The hardness was enhanced by Ho additions in as-cast and T6 states because of the formation of hard $\mathrm{Al}_{3} \mathrm{Ho}$ phases.

The corrosion-proof performance was enhanced by Ho addition and the T6 treatment due to increases of the corrosion potential.

Author Contributions: Data curation, Y.L.; Investigation, H.L. and N.L.; Methodology, R.Z.; Project administration, T.G.; Supervision, Z.S.; Validation, Hu; Writing—original draft, Q.W.

Funding: This research was funded by Inner Mongolia Science \& Technology Plan of China, 2018-01-068.

Acknowledgments: The authors would like to thank Tian Changming and Bai Xuefrng, Inner Mongolia Huomei-hongjun wheel manufacturing Co. Ltd.

Conflicts of Interest: The authors declare no conflict of interest.

\section{References}

1. Marzouk, M.; Jain, M.; Shankar, S. Effect of Sr-modification on the bendability of cast aluminum alloy A356 using digital image correlation method. Mater. Sci. Eng. A 2014, 598, 277-287. [CrossRef]

2. Mallapur, D.G.; Kor, S.A.; Udupa, K. Rajendra. Influence of Ti, B and Sr on the microstructure and mechanical properties of A356 alloy. J. Mater. Sci. 2011, 46, 1622-1627. [CrossRef]

3. Samuel, A.M.; Doty, H.W.; Valtierra, S.; Samuel, F.H. Effect of grain refining and Sr-modification interactions on the impact toughness of Al-Si-Mg cast alloys. Mater. Des. 2014, 56, 264-273. [CrossRef]

4. Tsai, Y.C.; Chou, C.Y.; Lee, S.L.; Lin, C.K.; Lin, J.C.; Lim, S.W. Effect of trace La addition on the microstructures and mechanical properties of A356 (Al-7Si-0.35Mg) aluminum alloys. J. Alloys Compd. 2009, 487, 157-162. [CrossRef]

5. Tsai, Y.C.; Lee, S.L.; Lin, C.K. Effect of trace Ce addition on the microstructures and mechanical properties of A356 (AL-7SI-0.35Mg) aluminum alloys. J. Chin. Inst. Eng. 2011, 34, 609-616. [CrossRef]

6. Tsai, Y.C.; Chou, C.Y.; Jeng, R.R.; Lee, S.L.; Lin, C.K. Effect of rare earth elements addition on microstructures and mechanical properties of A356 alloy. Int. J. Cast Meter. Res. 2011, 24, 83-87. [CrossRef]

7. Zhu, M.Z.; Jian, Y.; Yao, L.J.; Liu, C.X.; Yang, G.C.; Zhou, Y.H. Effect of mischmetal modification treatment on the microstructure, tensile properties, and fracture behavior of Al-7.0\%Si-0.3\%Mg foundry aluminum alloys. J. Mater. Sci. 2011, 46, 2685-2694. [CrossRef]

8. Patakham, U.; Kajornchaiyakul, J.; Limmaneevichitr, C. Grain refinement mechanism in an Al-Si-Mg alloy with scandium. J. Alloys Compd. 2012, 542, 177-186. [CrossRef]

9. Shi, Z.M.; Wang, Q.; Zhao, G.; Zhang, R.Y. Effects of erbium modification on the microstructure and mechanical properties of A356 aluminum alloys. Mater. Sci. Eng. A 2015, 626, 102-107. [CrossRef] 
10. Shi, Z.; Wang, Q.; Shi, Y.; Zhao, G.; Zhang, R. Microstructure and mechanical properties of Gd-modified A356 aluminum alloys. J. Rare Earths. 2015, 33, 1004-1009. [CrossRef]

11. Dong, Y.; Zheng, R.G.; Lin, X.P.; Ye, H.; Sun, L. Investigation on the modification behavior of A356 alloy inoculated with a Sr-Y composite modifier. J. Rare Earths 2013, 31, 204-207. [CrossRef]

12. Hu, X.W.; Jiang, F.G.; Ai, F.R.; Yan, H. Effects of rare earth Er additions on microstructure development and mechanical properties of die-cast ADC12 aluminum alloy. J. Alloys Compd. 2012, 538, 21-27. [CrossRef]

13. Gao, Z.; Li, H.; Lai, Y.; Ou, Y.; Li, D. Effects of minor Zr and Er on microstructure and mechanical properties of pure aluminum. Mater. Sci. Eng. A 2013, 580, 92-98. [CrossRef]

14. Xu, C.L.; Jiang, Q.C.; Yang, Y.F.; Wang, H.Y.; Wang, J.G. Effect of Nd on primary silicon and eutectic silicon in hypereutectic Al-Si alloys. J. Alloys Compd. 2006, 422, L1-L4. [CrossRef]

15. Xing, P.; Gao, F.B.; Zhuang, Y.X.; Liu, K.H.; Tu, G.F. Effect of Erbium on properties and microstructure of Al-Si eutectic alloy. J. Rare Earths 2010, 28, 927-929. [CrossRef]

16. Shi, Y.; Wang, Q.; Zhao, G. Effects of Gd and Ho modification on microstructure of Al-Si-Mg cast aluminum alloy. Chin. Rare Earths 2013, 34, 47-51.

17. Koleshko, V.M.; Belitskii, V.F.; Obukhov, V.E.; Rumak, N.V.; Urban, T.P. Crystal structure and phase composition of thin aluminum films containing additions of holmium. Rus. Metall. 1984, 5, 169-172.

18. Song, Y.L.; Liu, Y.H.; Zhu, X.Y.; Wang, W.-Q. Influence of Ho on corrosion behavior of AZ91 magnesium alloy. J. Jilin Univ. 2011, 41, 366-370.

19. Zhou, X.; Huang, Y.; Wei, Z.; Chen, Q.; Gan, F. Improvement of corrosion resistance of AZ91D magnesium alloy by holmium addition. Corr. Sci. 2006, 48, 4223-4233. [CrossRef]

20. Muga, C.O.; Zhao, Y.; Guo, H.; Xu, S.; Zou, Y.; Zhang, Z.W. Addition of Holmium and Erbium and Hot-Rolling Effects on the Microstructure and Mechanical Properties of Mg-Li Based Alloys. In Magnesium Technology 2017; Springer Nature Switzerland AG: Basel, Switzerland, 2017; pp. 463-470.

21. Muga, C.; Guo, H.; Zou, Y.; Xu, S.; Zhang, Z. Effects of holmium and hot-rolling on microstructure and mechanical properties of Mg-Li based alloys. J. Rare Earths 2016, 34, 1269-1276. [CrossRef]

22. Ahmad, R.; Shahizan, N.R.; Asmael, M.B.A.; Elaswad, A.M.M. The influence of holmium on the microstructure and hardness of Mg-Nd-Gd-Zn-Zr alloys. Key Eng. Mater. 2017, 740, 48-53. [CrossRef]

23. Sheng, L.; Wang, L.; Xi, T.; Zheng, Y.; Ye, H. Microstructure, precipitates and compressive properties of various holmium doped NiAl/Cr(Mo, Hf) eutectic alloys. Mater. Des. 2011, 32, 4810-4817. [CrossRef]

24. Guo, J.T.; Sheng, L.Y.; Tian, Y.X.; Zhou, L.Z.; Ye, H.Q. Effect of Ho on the microstructure and compressive properties of NiAl-based eutectic alloy. Mater. Lett. 2008, 62, 3910-3912. [CrossRef]

25. Tian, Y.X.; Guo, J.T.; Cheng, G.M.; Sheng, L.Y.; Zhou, L.Z.; He, L.L.; Ye, H.Q. Elevated temperature compressive behavior of Nb-22Ti-16Si-7Cr-3Al-3Ta-2Hf alloy with minor Ho addition. Mat. Res. Adv. Tech. 2008, 99, 228-232. [CrossRef]

26. Metal Department of Zhongshan University. Physicochemical Constants of Rare Earths; Metallurgical Industry Press: Beijing, China, 1978; pp. 56-58. (In Chinses)

27. Zhou, G.; Duan, L. Basis of Structural Chemistry, 1st ed.; Beijing University Press: Beijing, China, 2008; pp. 126-128. (In Chinses)

28. Nagasaki, S.M. Hirabayashi. Binary Alloy Phase-Diagrams; Agne Gijutsu Central Corporation. Lid: Tokyo, Japan, 2002; pp. 31-43.

29. Sun, W.H.; Zhang, S.R.; Hou, A.Q. Behaviors of Rare Earths in Aluminum Alloys; Weapon Industry Press: Beijing, China, 1992; pp. 58-65. (In Chinses)

30. Rahimipour, M.R.; Momeni, M.; Naseri, T. Microstructure and grain refining performance of a new Al-Ti-C master alloy. IJE Tran. A 2013, 26, 701-706. [CrossRef]

31. Wang, T.M.; Fu, H.W.; Chen, Z.N.; Xu, J.; Zhu, J.; Cao, F.; Li, T.J. A novel fading-resistant Al-3Ti-3B grain refiner for Al-Si alloys. J. Alloys Compd. 2012, 511, 45-49. [CrossRef]

32. Zhao, H.L.; Yue, J.S.; Gao, Y.; Weng, K.R. Grain and dendrite refinement of A356 alloy with Al-Ti-C-RE master alloy. Rare Met. 2013, 32, 12-17. [CrossRef]

33. Campbell, J.; Tiryakioglu, M. Review of effect of P and Sr on modification and porosity development in Al-Si alloys. Mater. Sci. Tech. 2010, 26, 262-268. [CrossRef] 
34. Srirangam, P.; Chattopadhyay, S.; Bhattacharya, A.; Nag, S.; Kaduk, J.; Shankar, S.; Banerjee, R.; Shibata, T. Probing the local atomic structure of Sr-modified Al-Si alloys. Acta Mater. 2014, 65, 185-193. [CrossRef]

35. Eremenko, V.N.; Listovnichii, V.E.; Luzan, S.P.; Buyanov, Y.I.; Martsenyuk, P.S. Phase diagram of the holmium-silicon binary system and physical properties of holmium silicides up to $1050{ }^{\circ} \mathrm{C}$. J. Alloys Compd. 1995, 219, 181-184. [CrossRef]

36. Okamoto, H. Al-Ho (Aluminum-Holmium). J. Phase Equilib. Diff. 2011, 32, 1. [CrossRef]

37. Forn, A.; Baile, M.T.; Martin, E.; Rupérez, E. Effect of heat treatments in the silicon eutectic crystal evolution in Al-Si alloys. Mater. Sci. Forum 2005, 480, 367-372. [CrossRef]

(C) 2018 by the authors. Licensee MDPI, Basel, Switzerland. This article is an open access article distributed under the terms and conditions of the Creative Commons Attribution (CC BY) license (http:/ / creativecommons.org/licenses/by/4.0/). 